\title{
An Improved Approach for Parameterizing Surface-Layer Turbulent Transfer Coefficients in Numerical Models
}

\author{
Yubin Li • Zhiqiu Gao • Donald H. Lenschow • \\ Fei Chen
}

Received: 28 January 2010 / Accepted: 21 June 2010 / Published online: 16 July 2010

(C) Springer Science+Business Media B.V. 2010

\begin{abstract}
Based on classic iterative computation results, new equations to calculate the surface turbulent transfer coefficients are proposed, which allow for large ratios of the momentum and heat roughness lengths. Compared to the Launiainen scheme, our proposed scheme generates results closer to classical iterative computations. Under unstable stratification, the relative error in the Launiainen scheme increases linearly with increasing instability, even exceeding $15 \%$, while the relative error of the present scheme is always less than $8.5 \%$. Under stable stratification, the Launiainen scheme uses two equations, one for $0<R i_{\mathrm{B}} \leq 0.08$ and another for $0.08<R i_{\mathrm{B}} \leq 0.2$, and does not consider the condition that $R i_{\mathrm{B}}>0.2$, while its relative errors in the region $0<R i_{\mathrm{B}} \leq 0.2$ exceed 31 and $24 \%$ for momentum and heat transfer coefficients, respectively. In contrast, the present scheme uses only one equation for $0<R i_{\mathrm{B}} \leq 0.2$ and another equation for $R i_{\mathrm{B}}>0.2$, and the relative error of the present scheme is always less than $14 \%$.
\end{abstract}

Keywords Numerical model parameterizations · Surface exchange · Transfer coefficients

\section{Introduction}

The development of adequate parameterizations of surface turbulent fluxes in numerical models has been an important research topic (e.g., ECMWF 1988; Garratt and Pielke 1989), because the exchange process cannot be explicitly modelled. As an essential basis for numerous surface-layer studies, the Monin-Obukhov similarity theory (Monin and Obukhov 1954) has been widely used to characterize boundary-layer stratification and the turbulent fluxes

Y. Li · Z. Gao

State Key Laboratory of Atmospheric Boundary Layer Physics and Atmospheric Chemistry, Institute of Atmospheric Physics, CAS, Beijing 100029, China

D. H. Lenschow $(\varangle) \cdot$ F. Chen

National Center for Atmospheric Research (NCAR), Boulder, CO, USA

e-mail: lenschow@ucar.edu 
emanating from the Earth's surface. In this theory, vertical gradients of the mean wind speed $(u)$ and mean potential temperature $(\theta)$ are related to the surface fluxes by the relations:

$$
\begin{gathered}
\partial u / \partial z=u_{*} \phi_{\mathrm{m}}(\zeta) / k z, \\
\partial \theta / \partial z=\theta_{*} \phi_{\mathrm{h}}(\zeta) / k z,
\end{gathered}
$$

where $u_{*}$ is the friction velocity, $\theta_{*}$ is the temperature scale, $k$ is the von Karman constant, $z$ is the altitude, and $\zeta$ is the stability parameter, $\zeta=z / L$, where $L$ is the Obukhov length, defined as: $L \equiv u_{*}^{2} \bar{\theta} /\left(k g \theta_{*}\right)$. The momentum function $\left(\varphi_{\mathrm{m}}\right)$ and heat function $\left(\varphi_{\mathrm{h}}\right)$ are assumed universal and are deduced from observations (Guilloteau 1998).

The vertical profiles of $u$ and of $\theta$ can then be obtained by integrating the flux-profile relationships given above,

$$
\begin{gathered}
u=\frac{u_{*}}{k}\left[\ln \left(\frac{z}{z_{0}}\right)-\psi_{\mathrm{m}}\left(\frac{z}{L}\right)+\psi_{\mathrm{m}}\left(\frac{z_{0}}{L}\right)\right], \\
\Delta \theta=\theta-\theta_{0}=\frac{R \theta_{*}}{k}\left[\ln \left(\frac{z}{z_{0 \mathrm{~h}}}\right)-\psi_{\mathrm{h}}\left(\frac{z}{L}\right)+\psi_{\mathrm{h}}\left(\frac{z_{0 \mathrm{~h}}}{L}\right)\right],
\end{gathered}
$$

where $\theta_{0}$ is the potential temperature at height $z_{0 \mathrm{~h}}, R$ is the Prandtl number, $z_{0}$ is the aerodynamic roughness length, $z_{0 \mathrm{~h}}$ is the roughness length for temperature, and $\psi_{\mathrm{m}}$ and $\psi_{\mathrm{h}}$ are the integrated stability functions for momentum and heat, respectively. The turbulent fluxes of momentum $(\tau)$ and heat $(H)$ are calculated from the bulk relations:

$$
\begin{gathered}
\tau \equiv \rho u_{*}^{2}=\rho C_{\mathrm{M}} u^{2}, \\
H \equiv-\rho c_{p} u_{*} \theta_{*}=-\rho c_{p} C_{\mathrm{H}} u\left(\theta-\theta_{0}\right),
\end{gathered}
$$

where $c_{p}$ is the specific heat capacity at constant pressure, $C_{\mathrm{M}}$ is the drag coefficient and $C_{\mathrm{H}}$ is the heat transfer coefficient. Substituting Eqs. 2 and 3 into Eqs. 4 and 5, and solving for $C_{\mathrm{M}}$ and $C_{\mathrm{H}}$ gives

$$
\begin{gathered}
C_{\mathrm{M}}=\frac{k^{2}}{\left[\ln \left(z / z_{0}\right)-\psi_{\mathrm{m}}(z / L)+\psi_{\mathrm{m}}\left(z_{0} / L\right)\right]^{2}}, \\
C_{\mathrm{H}}=\frac{k^{2} / R}{\left[\ln \left(z / z_{0}\right)-\psi_{\mathrm{m}}(z / L)+\psi_{\mathrm{m}}\left(z_{0} / L\right)\right]\left[\ln \left(z / z_{0}\right)-\psi_{\mathrm{h}}(z / L)+\psi_{\mathrm{h}}\left(z_{0 \mathrm{~h}} / L\right)\right]} .
\end{gathered}
$$

In the past 40 years, both $\psi_{\mathrm{m}}$ and $\psi_{\mathrm{h}}$ have been extensively investigated and several formulations have been proposed (e.g., Businger et al. 1971; Dyer 1974; Holtslag and de Bruin 1988; Beljaars and Holtslag 1991; Högström 1996). So far, the most accurate formulations seem to be those of Högström (1996) for unstable stratification and of Beljaars and Holtslag (1991) for stable stratification resulting from improvements in observational techniques (Guilloteau 1998). In Eqs. 2, 3, 6, and 7, $u$ and $\theta$ are obtained from the model computation at the first grid level, but $u_{*}, \theta_{*}$, and $L$ must adjust to each other in order to obtain $\tau$ and $H$, so iteration procedures become necessary.

In early mesoscale numerical models, $u$ and $\theta$ were the values at the first grid level of the model, and an iterative computational method, together with a first guess approximation to $u_{*}$, were usually used to estimate $\tau$ and $H$. Because this iteration is needed for all grid nodes of the lowest level of the atmospheric model at all timesteps, the iteration takes considerable computing time, especially for a high horizontal resolution simulation over a large region. In the Coupled Ocean-Atmosphere Response Experiment (COARE) algorithm, Fairall et al. (1996) used 'the first best guess' for $u_{*}$ to obtain $\tau$ with limited iterations. 
For this reason, in the past 30 years, considerable effort has been made to avoid numerical iterations. Based on the flux-profile relationships of Businger et al. (1971), Louis (1979) proposed a compact scheme where the bulk Richardson number $\left(R i_{\mathrm{B}}\right)$, instead of the Obukhov length $(L)$, was used for the parameterization of $u_{*}^{2}$ and $u_{*} \theta_{*}$ because $R i_{\mathrm{B}}$ can be calculated from routine observations. Later, Louis et al. (1982) revised the original scheme by slightly changing the coefficients in the functions. This scheme has been widely used in atmospheric models due to its simplicity in formulation and non-iterative nature (Wang et al. 2002). Since then, there has been considerable effort on analytical (non-iterative) schemes. Garratt (1992) suggested an extension of the Louis scheme in which certain constants are determined by least-squares fitting for values of the roughness ratio $z_{0} / z_{0 \mathrm{~h}}$ different from unity. Mascart et al. (1995) improved the surface-layer flux-profile relations of Louis (1979) to allow for different values of the momentum and temperature roughness lengths for most natural land surface types. Using a flux-profile iteration procedure, Launiainen (1995) obtained a semi-analytical relationship between the Obukhov stability parameter $z / L$ and the bulk Richardson number $R i_{\mathrm{B}}$ for variables $z_{0}$ and $z_{0} / z_{0 \mathrm{~h}}$. Uno et al. (1995) extended the surface-flux calculation method proposed by Louis (1979) by allowing momentum and heat roughness lengths to have different values, which leads to a re-definition of the bulk Richardson number. Van den Hurk and Holtslag (1997) compared various parameterizations for the bulk transfer coefficients for heat and momentum over wide ranges of atmospheric stability, $z_{0}$ and $z_{0 \mathrm{~h}}$. Delage (1997) compared five different formulations of the stability functions used for vertical transfer in atmospheric models in a one-dimensional model of the nocturnal boundary layer. Kot and Song (1998) improved the Louis scheme (1979) by broadening the original assumptions and, based on state-of-the-art empirical flux-profile relationships, Guilloteau (1998) proposed a new method for computation of the surface momentum and heat transfer coefficients. Wang et al. (2002) briefly reviewed previous non-iterative schemes and proposed improvements to the Louis surface-flux parameterizations (Louis 1979; Louis et al. 1982). Building on most of the prior studies, especially Launiainen (1995), the present study proposes a new relationship between $z / L$ and the bulk Richardson number $R i_{\mathrm{B}}$, which allows for non-iterative approaches to the calculation of turbulent fluxes and incorporates a non-unity $z_{0} / z_{00 \mathrm{~h}}$.

\section{Relationship Between $z / L$ and $R i_{\mathrm{B}}$}

Near the surface, stratification may be specified in terms of $\zeta$, or the bulk Richardson number $R i_{\mathrm{B}}$, which is usually expressed as

$$
R i_{\mathrm{B}}=g z \Delta \theta /\left(u^{2} \bar{\theta}\right) .
$$

From flux-profile equations 2 and 3, we obtain

$$
\zeta=\frac{R i_{\mathrm{B}}}{R} \frac{\left[\ln \left(z / z_{0}\right)-\psi_{\mathrm{m}}(z / L)+\psi_{\mathrm{m}}\left(z_{0} / L\right)\right]^{2}}{\left[\ln \left(z / z_{0 \mathrm{~h}}\right)-\psi_{\mathrm{h}}(z / L)+\psi_{\mathrm{h}}\left(z_{0 \mathrm{~h}} / L\right)\right]} .
$$

In mesoscale models, the lowest level is usually at about $10 \mathrm{~m}$, so we take $z=10 \mathrm{~m}$ as a constant in this study. Following Louis (1979), we discuss the following five cases: $z / z_{0}=$ $100,400,2000,10^{4}$, and $10^{5}$, corresponding to $z_{0}=0.1,0.025,0.005,10^{-3}$, and $10^{-4} \mathrm{~m}$ (for the case that $z / z_{0}$ is smaller than $1 / 10$, the present scheme is inapplicable). These cases roughly correspond to agricultural fields, desert, ice surface, rough sea surface and smooth sea surface, respectively (Garratt 1992). For $z_{0 \mathrm{~h}}$, we set the range as $0.5<z_{0} / z_{0 \mathrm{~h}}<100$. To increase the accuracy of the new scheme, the stratification conditions are classified as: unstable $\left(R i_{\mathrm{B}}<0\right)$, weakly stable $\left(0<R i_{\mathrm{B}} \leq 0.2\right)$ and strongly stable $\left(R i_{\mathrm{B}}>0.2\right)$. 
2.1 Unstable Stratification $\left(R i_{\mathrm{B}}<0\right)$

Launiainen (1995) suggested a linear relationship between $\zeta$ and $R i_{\mathrm{B}}$ for unstable conditions:

$$
\zeta=\left[\ln ^{2}\left(z / z_{0}\right) / \ln \left(z_{0} / z_{0 \mathrm{~h}}\right)-0.55\right] R i_{\mathrm{B}} .
$$

However, as shown in Fig. 1, the results of the Launiainen (1995) scheme differ from the Högström (1996) scheme when $R i_{\mathrm{B}}$ decreases for unstable stratification. To better approach the results of Högström (1996), we assume a quadratic relationship between $\zeta$ and $R i_{\mathrm{B}}$ for unstable conditions, that is

$$
\zeta=A R i_{\mathrm{B}}^{2}+B R i_{\mathrm{B}}
$$

where $A$ and $B$ are coefficients related to the roughness conditions $z / z_{0}$ and $z_{0} / z_{0}$ h. By regression analysis and a significance test, and to ensure the mean deviation from iteration results stays less than $5 \%$, we obtain the following equation:

$$
\zeta=a_{\mathrm{u} 11} \alpha R i_{\mathrm{B}}^{2}+\left[\left(b_{\mathrm{u} 11} \beta+b_{\mathrm{u} 12}\right) \alpha^{2}+\left(b_{\mathrm{u} 21} \beta+b_{\mathrm{u} 22}\right) \alpha+\left(b_{\mathrm{u} 31} \beta^{2}+b_{\mathrm{u} 32} \beta+b_{\mathrm{u} 33}\right)\right] R i_{\mathrm{B}},
$$

where $\alpha=\ln \left(z / z_{0}\right), \beta=\ln \left(z_{0} / z_{0 \mathrm{~h}}\right)$, and the coefficients $a_{\mathrm{u} 11}=0.0450, b_{\mathrm{u} 11}=0.0030$, $b_{\mathrm{u} 12}=0.0059, b_{\mathrm{u} 21}=-0.0828, b_{\mathrm{u} 22}=0.8845, b_{\mathrm{u} 31}=0.1739, b_{\mathrm{u} 32}=-0.9213$, and $b_{\mathrm{u} 33}=-0.1057$.

2.2 Weakly Stable Condition $\left(0<R i_{\mathrm{B}} \leq 0.2\right)$

For $0<R i_{\mathrm{B}} \leq 0.2$, Launiainen (1995) suggested

$$
\zeta=\left\{\begin{array}{ll}
{\left[\ln \left(z / z_{0}\right) /\left(1-5.2 R i_{\mathrm{B}}\right)-1.3 \ln \left(z_{0} / z_{0 \mathrm{~h}}\right)\right] R i_{\mathrm{B}}} & 0<R i_{\mathrm{B}} \leq 0.08 \\
{\left[1.89 \ln \left(z / z_{0}\right)+44.2\right] R i_{\mathrm{B}}^{2}} & \\
+\left[1.18 \ln \left(z_{2} / z_{0}\right)-1.5 \ln \left(z_{0} / z_{0 \mathrm{~h}}\right)-1.37\right] R i_{\mathrm{B}} & 0.08<R i_{\mathrm{B}} \leq 0.2
\end{array} .\right.
$$

We found by regression analysis and a significance test that a quadratic relationship between $\zeta$ and $R i_{\mathrm{B}}$ throughout the entire domain is useful. The resulting equation is

$$
\begin{aligned}
\zeta= & {\left[\left(a_{\mathrm{w} 11} \beta+a_{\mathrm{w} 12}\right) \alpha+\left(a_{\mathrm{w} 21} \beta+a_{\mathrm{w} 22}\right)\right] R i_{\mathrm{B}}^{2}+\left[\left(b_{\mathrm{w} 11} \beta+b_{\mathrm{w} 12}\right) \alpha+\left(b_{\mathrm{w} 21} \beta\right.\right.} \\
& \left.\left.+b_{\mathrm{w} 22}\right)\right] R i_{\mathrm{B}},
\end{aligned}
$$

where $a_{\mathrm{w} 11}=0.5738, a_{\mathrm{w} 12}=-0.4399, a_{\mathrm{w} 21}=-4.901, a_{\mathrm{w} 22}=52.50, b_{\mathrm{w} 11}=-0.0539$, $b_{\mathrm{w} 12}=1.540, b_{\mathrm{w} 21}=-0.6690$, and $b_{\mathrm{w} 22}=-3.282$.

\subsection{Strongly Stable Stratification $\left(R i_{\mathrm{B}}>0.2\right)$}

Launiainen (1995) did not discuss the relationship between $\zeta$ and $R i_{\mathrm{B}}$ for strongly stable stratification, so we assume a linear relationship between $\zeta$ and $R i_{\mathrm{B}}$ :

$$
\zeta=A R i_{\mathrm{B}}+B
$$

By again using regression analysis and a significance test, the coefficients are determined as:

$$
\zeta=\left(a_{\mathrm{s} 11} \alpha+a_{\mathrm{s} 21}\right) R i_{\mathrm{B}}+b_{\mathrm{s} 11} \alpha+b_{\mathrm{s} 21} \beta+b_{\mathrm{s} 22},
$$

where $a_{\mathrm{s} 11}=0.7529, a_{\mathrm{s} 21}=14.94, b_{\mathrm{s} 11}=0.1569, b_{\mathrm{s} 21}=-0.3091$, and $b_{\mathrm{s} 22}=-1.303$. 

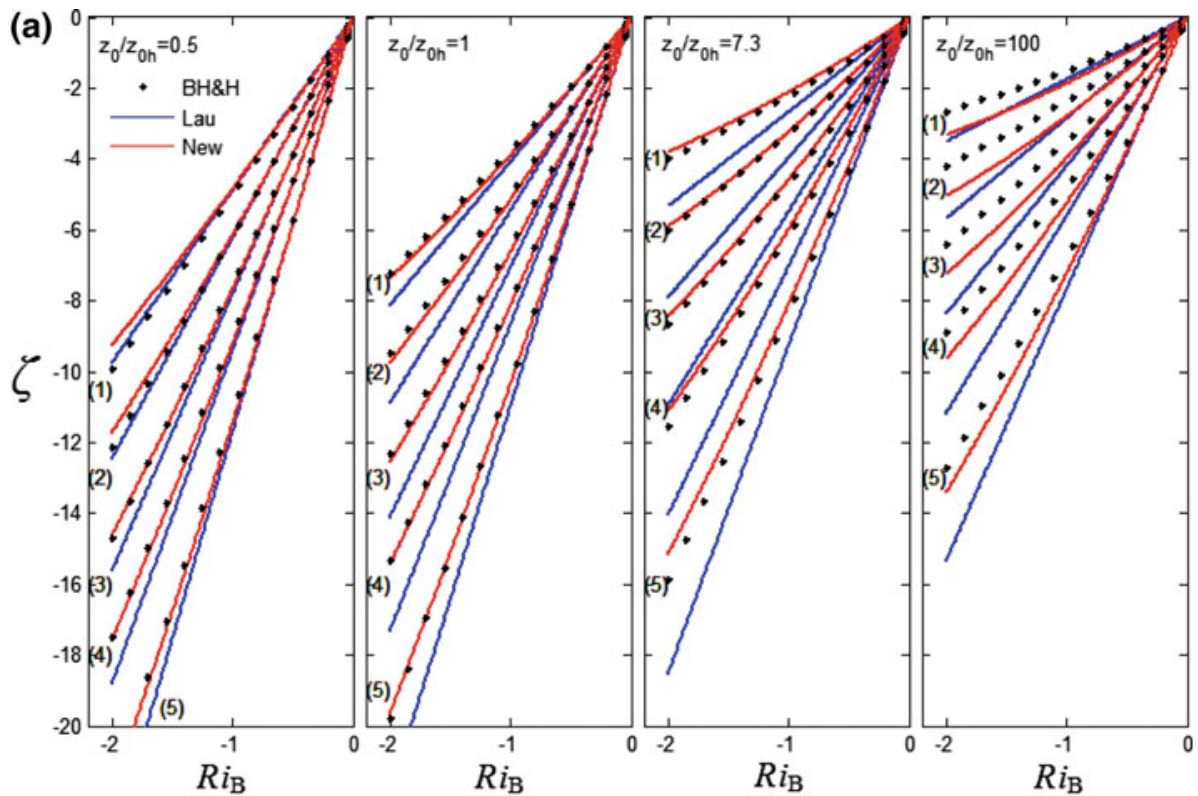

(b)
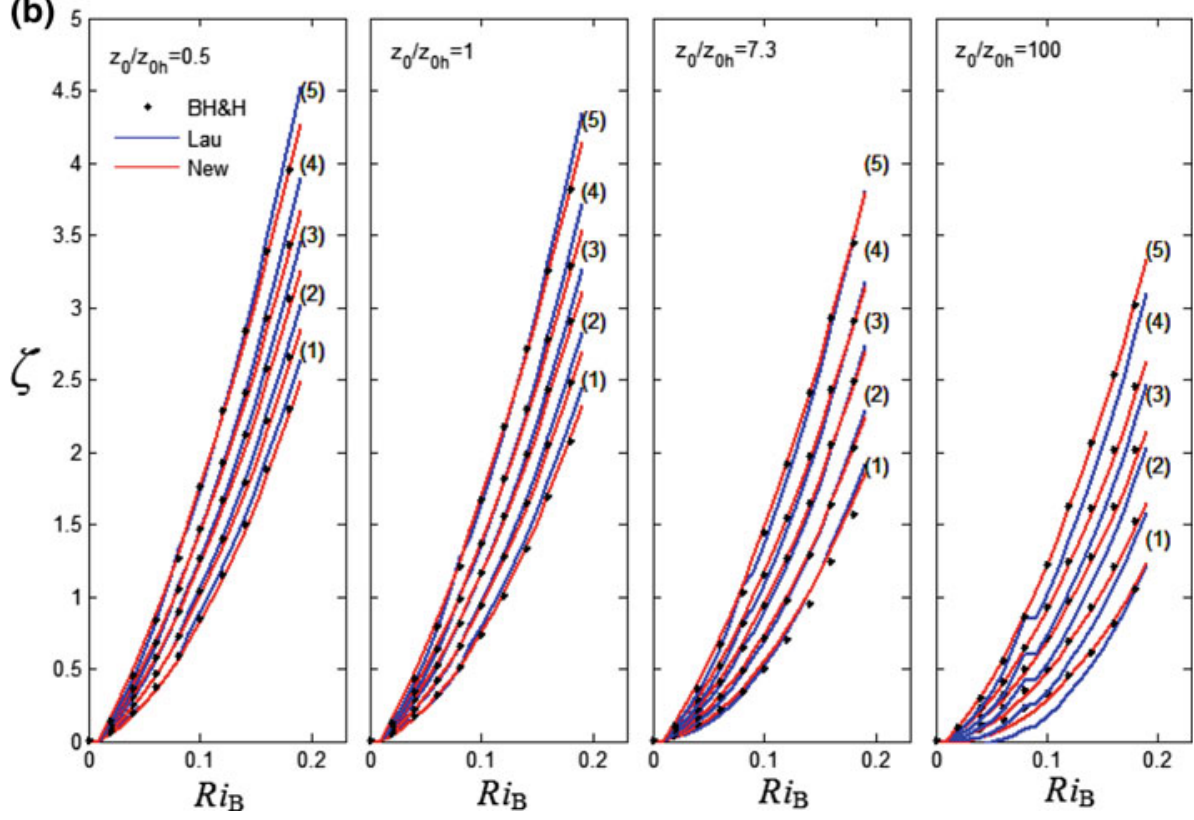

Fig. 1 The relationship between the stability parameter $\zeta$ and Richardson number $R i_{\mathrm{B}}$ in the $\mathrm{BH} \& \mathrm{H}$ scheme (black dots), the Launiainen scheme (blue line) and the new scheme (red line). a, b and $\mathbf{c}$ represent unstable, weakly stable and strongly stable conditions separately, while (1), (2), (3), (4) and (5) represent $z / z_{0}=$ $100,400,2000,10^{4}$ and $10^{5}$ separately

So far, we have obtained the equations to calculate $\zeta$ by using $R i_{\mathrm{B}}, z / z_{0}$, and $z_{0} / z_{0 \mathrm{~h}}$ for all stratification conditions, where $z / z_{0}$ ranges from $10^{2}$ through $10^{5}$, and $z_{0} / z_{0 \mathrm{~h}}$ ranges from 0.5 through 100 . We apply $\zeta$ obtained above into the universal functions of the Högström 


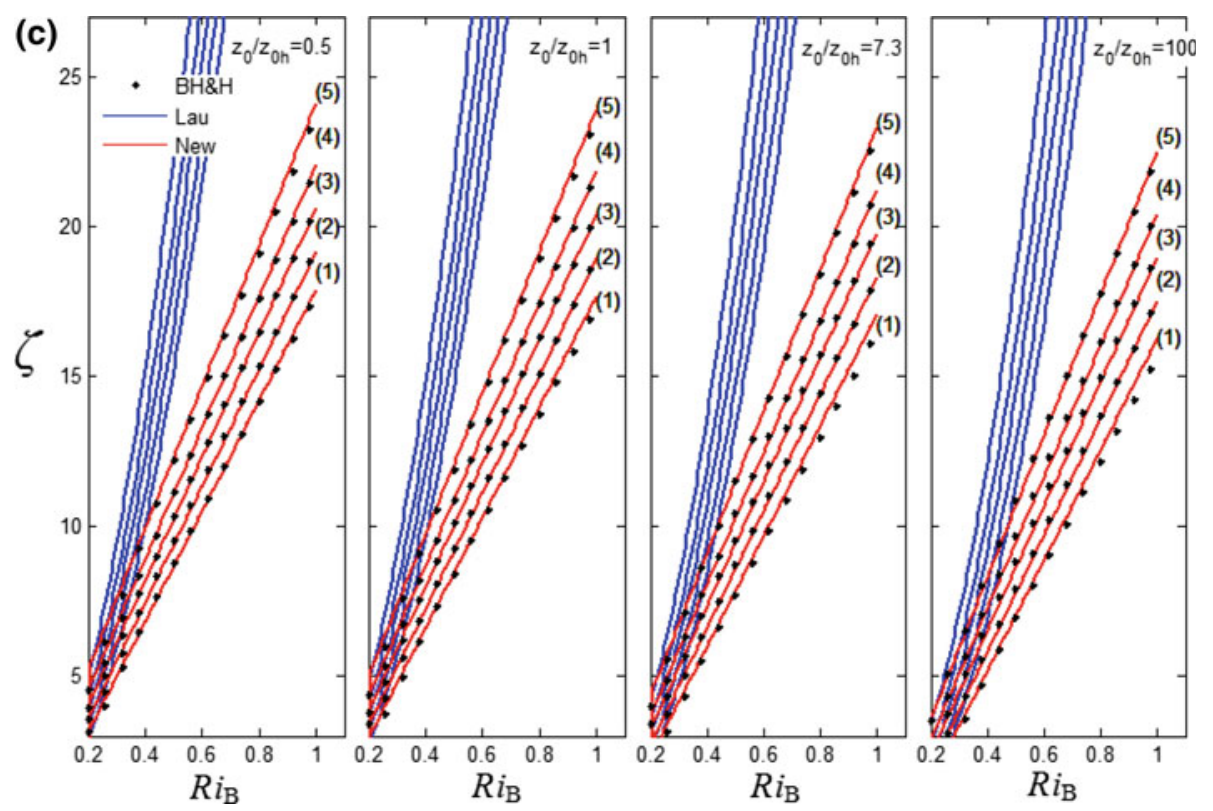

Fig. 1 continued

(1996) scheme for unstable conditions, and the Beljaars and Holtslag (1991) scheme for stable conditions, and then substitute these universal functions into Eqs. 6-7 to obtain $C_{\mathrm{M}}$ and $C_{\mathrm{H}}$.

\section{Results}

The relationships between $\zeta$ and $R i_{\mathrm{B}}$, estimated by using the Launiainen (1995) scheme, are compared with those obtained above in Fig. 1, where the results obtained by using the original iterative schemes of Högström (1996) (unstable stratification) and of Beljaars and Holtslag (1991) (stable stratification) are also given for reference. For brevity, the Högström (1996) and Beljaars and Holtslag (1991) schemes are combined and called the BH\&H scheme. As mentioned in the introduction, so far the most accurate scheme in use is the BH\&H scheme; therefore, the $\mathrm{BH} \& \mathrm{H}$ scheme is used as a reference. The Launiainen scheme has two limits of application: (i) $-0.35 \leq R i_{\mathrm{B}} \leq 0.2$, and (ii) $0.5 \leq z_{0} / z_{0 \mathrm{~h}} \leq 7.3$ (Launiainen 1995). To facilitate comparison, we extend the range to (i) $-2 \leq R i_{\mathrm{B}} \leq 1$, and (ii) $0.5 \leq z_{0} / z_{0 \mathrm{~h}} \leq 100$. Figure 1 shows that:

(1) For unstable stratification $\left(R i_{\mathrm{B}}<0\right)$, the difference between the Launiainen (1995) scheme and the $\mathrm{BH} \& \mathrm{H}$ scheme becomes more significant when instability increases (i.e., $R i_{\mathrm{B}}$ decreases), and the values of $\zeta$ (blue lines) calculated by using $R i_{\mathrm{B}}$ in the Launiainen scheme (Eq. 11) are systematically lower than those (black dots) obtained by using iterative computations via the BH\&H scheme. Our scheme (i.e., Eq. 12) avoids iteration and generates results (red lines) that are closer to those (black dots) obtained by using iterative computations in the $\mathrm{BH} \& \mathrm{H}$ scheme.

(2) For weakly stable stratification $\left(0<R i_{\mathrm{B}} \leq 0.2\right)$, the Launiainen scheme and our scheme generate coincident results because the quadratic equations (i.e., Eqs. 14 

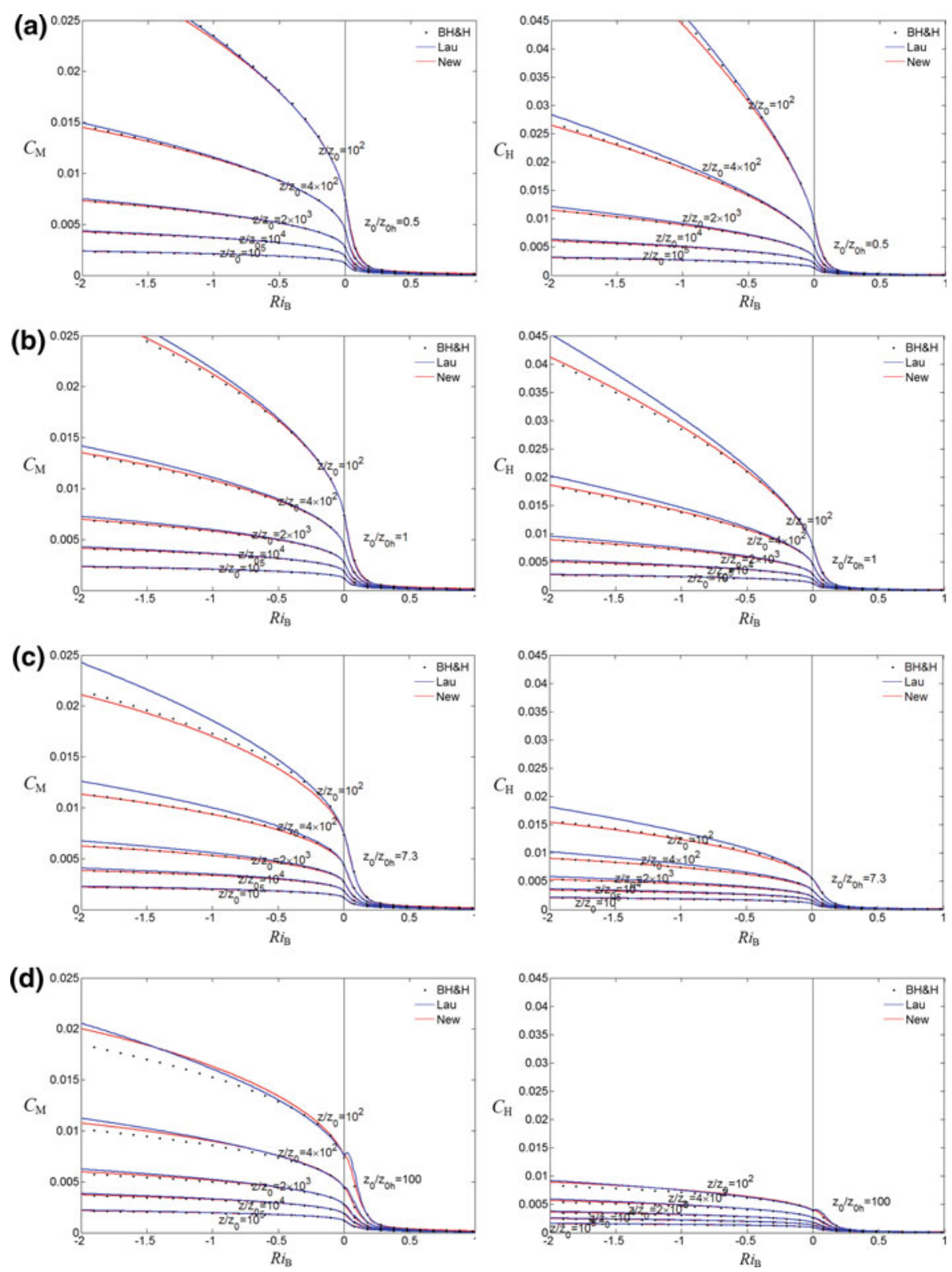

Fig. 2 The relationship between $C_{\mathrm{M}}\left(C_{\mathrm{H}}\right)$ and Richardson number $R i_{\mathrm{B}}$, calculated by using the $\mathrm{BH} \& \mathrm{H}$ scheme (black dots), the Launiainen scheme (blue line) and the new scheme (red line) 

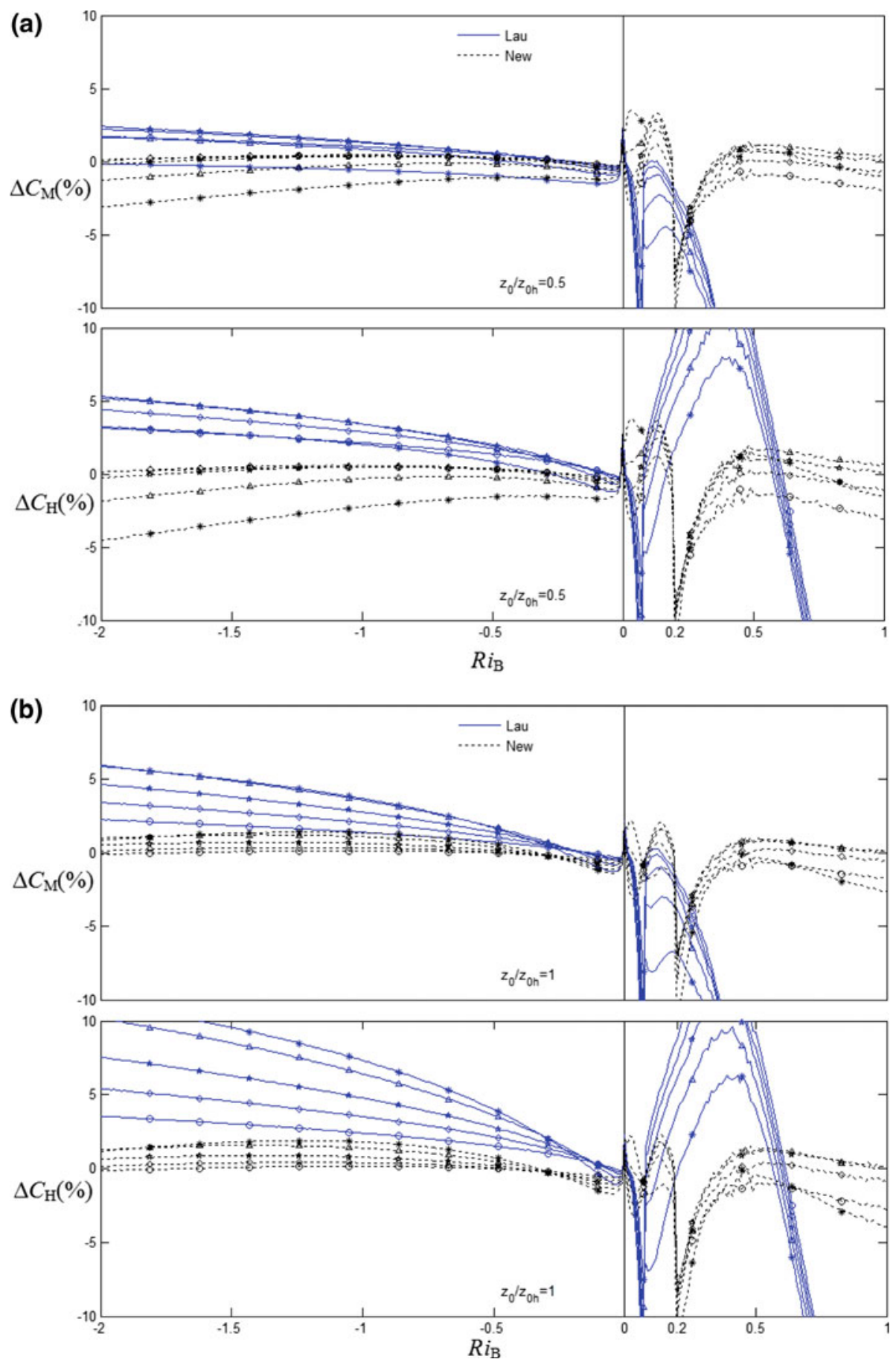

Fig. 3 The relative error in the turbulent flux transfer coefficients (against the BH\&H scheme) for the Launiainen scheme (blue line) and the new scheme (black dashed line), while stars, triangles, pentacles, diamonds and circles represent $z / z_{0}=100,400,2000,10^{4}$ and $10^{5}$ separately 

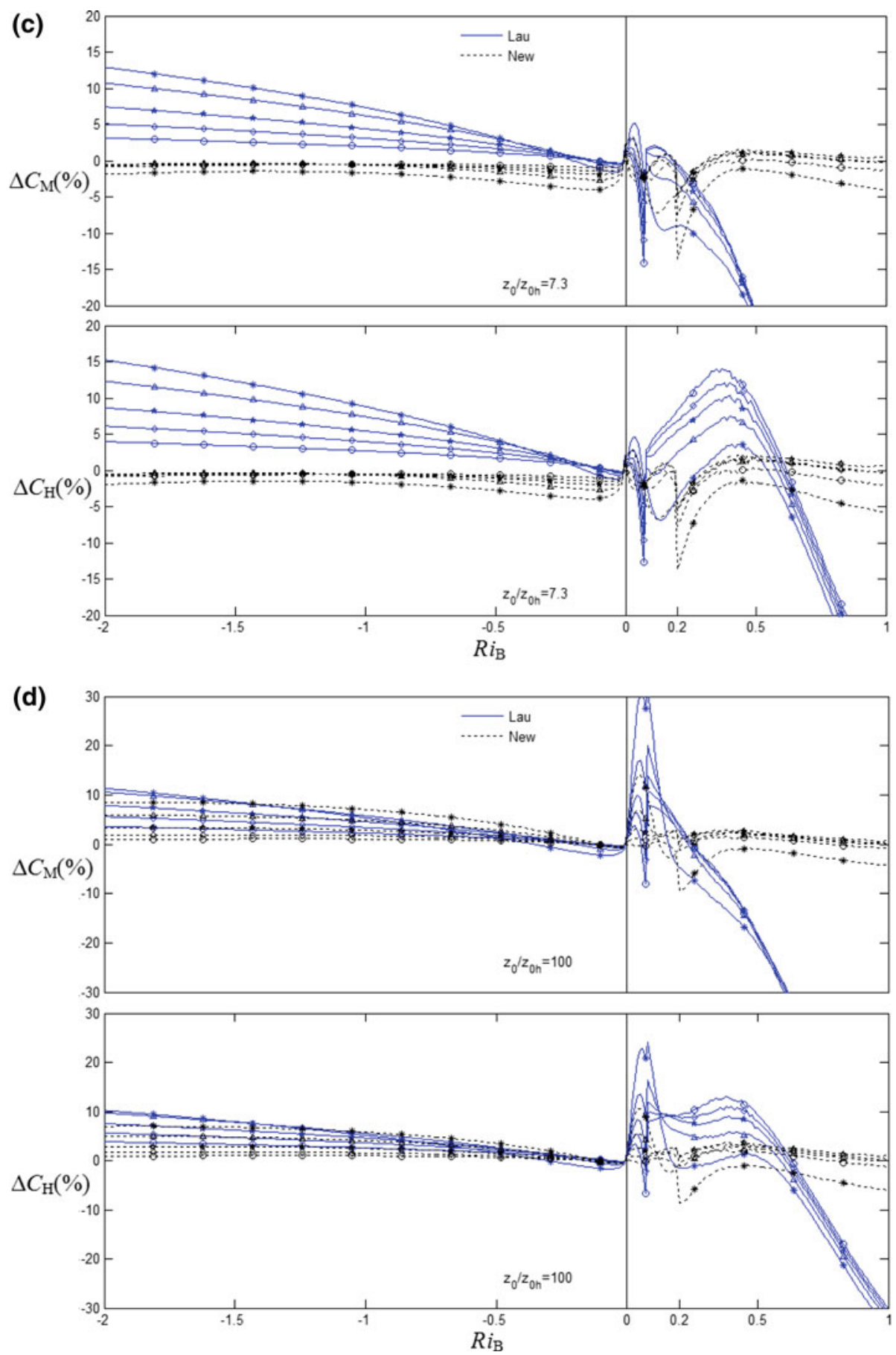

Fig. 3 continued 
and 15) are applied in regression for both of them, although the Launiainen scheme has a bias when $z_{0} / z_{0 \mathrm{~h}}=100$.

(3) For strongly stable stratification, our linear regression equation (i.e., Equation (16)) generates results that are consistent with those obtained by iterative computations with the BH\&H scheme. The Launiainen scheme is essentially not applicable for this condition.

The momentum and heat transfer coefficients calculated by using the BH\&H scheme, the Launiainen scheme, and our scheme are shown in Fig. 2. It is obvious that our approach gives results that are close to those obtained with the BH\&H scheme. To quantify the differences between the Launiainen scheme and our approach using the BH\&H scheme, we define a relative error (in percentage):

$$
\Delta C_{\mathrm{M}, \mathrm{H}}=100 \frac{\left(C_{\mathrm{M}, \mathrm{H}}-C_{\mathrm{M}, \mathrm{H}(\mathrm{BH} \& \mathrm{H})}\right)}{C_{\mathrm{M}, \mathrm{H}(\mathrm{BH} \& \mathrm{H})}},
$$

where $C_{\mathrm{M}, \mathrm{H}}$ is the turbulent momentum (or heat) flux transfer coefficient calculated from the Launiainen scheme or our approach, and $C_{\mathrm{M}, \mathrm{H}(\mathrm{BH} \& \mathrm{H})}$ is from the $\mathrm{BH} \& \mathrm{H}$ scheme. The relative errors, plotted in Fig. 3, show that the results of $\Delta C_{\mathrm{M}, \mathrm{H}}$ generated by using the present approaches are concentrated around the $x$ axis while the Launiainen scheme generates larger values of $\Delta C_{\mathrm{M}, \mathrm{H}}$.

For unstable stratification, the Launiainen scheme error increases linearly with increasing instability (i.e., decreasing $R i_{\mathrm{B}}$ ) and the largest error exceeds $15 \%$, while the largest errors for $C_{\mathrm{M}}$ and $C_{\mathrm{H}}$ in our approach are 8.5 and $7.0 \%$, respectively. In stable stratification, there is a discontinuity at $R i_{\mathrm{B}}=0.08$ with the Launiainen scheme and a discontinuity at $R i_{\mathrm{B}}=0.2$ with our scheme. The Launiainen scheme error increases dramatically with increasing stability; the largest errors for $C_{\mathrm{M}}$ and $C_{\mathrm{H}}$ are 67 and $37 \%$ (the values are too large to show in

Table 1 Largest absolute percentage $C_{\mathrm{M}}$ error for the Launiainen scheme and our scheme

\begin{tabular}{|c|c|c|c|c|c|c|c|c|c|}
\hline & $\begin{array}{l}R i_{\mathrm{B}}= \\
-2.00\end{array}$ & $\begin{array}{l}R i_{\mathrm{B}}= \\
-1.00\end{array}$ & $\begin{array}{l}R i_{\mathrm{B}}= \\
-0.01\end{array}$ & $\begin{array}{l}R i_{\mathrm{B}}= \\
0.01\end{array}$ & $\begin{array}{l}R i_{\mathrm{B}}= \\
0.07\end{array}$ & $\begin{array}{l}R i_{\mathrm{B}}= \\
0.09\end{array}$ & $\begin{array}{l}R i_{\mathrm{B}}= \\
0.19\end{array}$ & $\begin{array}{l}R i_{\mathrm{B}}= \\
0.21\end{array}$ & $\begin{array}{l}R i_{\mathrm{B}}= \\
1.00\end{array}$ \\
\hline $\begin{array}{l}\text { Launiainen } \\
\text { scheme, } \\
z_{0} / z_{0 h}=0.5\end{array}$ & 2.4 & 1.4 & 0.8 & 0.2 & 17.7 & 6.0 & 4.7 & 5.3 & 66.6 \\
\hline $\begin{array}{c}\text { Present scheme, } \\
z_{0} / z_{0 h}=0.5\end{array}$ & 3.1 & 1.6 & 0.7 & 2.1 & 2.8 & 2.3 & 1.1 & 8.9 & 2.0 \\
\hline $\begin{array}{l}\text { Launiainen } \\
\text { scheme, } \\
z_{0} / z_{0 \mathrm{~h}}=1.0\end{array}$ & 5.9 & 3.7 & 0.8 & 0.1 & 16.8 & 8.0 & 6.8 & 7.1 & 66.2 \\
\hline $\begin{array}{c}\text { Present scheme, } \\
z_{0} / z_{0 h}=1.0\end{array}$ & 1.0 & 1.3 & 0.9 & 1.7 & 1.7 & 1.7 & 2.4 & 10.4 & 2.7 \\
\hline $\begin{array}{l}\text { Launiainen } \\
\text { scheme, } \\
z_{0} / z_{0 h}=7.3\end{array}$ & 12.9 & 7.4 & 0.9 & 2.5 & 14.2 & 4.7 & 9.0 & 8.9 & 65.1 \\
\hline $\begin{array}{c}\text { Present scheme, } \\
z_{0} / z_{0 h}=7.3\end{array}$ & 1.9 & 1.7 & 1.5 & 2.3 & 2.5 & 5.5 & 4.8 & 12.1 & 4.1 \\
\hline $\begin{array}{l}\text { Launiainen } \\
\text { scheme, } \\
z_{0} / z_{0 h}=100\end{array}$ & 11.3 & 5.7 & 1.0 & 8.3 & 27.6 & 27.4 & 4.9 & 5.1 & 63.5 \\
\hline $\begin{array}{l}\text { Present scheme, } \\
z_{0} / z_{0 h}=100\end{array}$ & 8.4 & 7.0 & 0.5 & 5.6 & 11.5 & 7.1 & 2.8 & 9.4 & 4.3 \\
\hline
\end{tabular}


Table 2 Largest absolute percentage $C_{\mathrm{H}}$ error for the Launiainen scheme and our scheme

\begin{tabular}{|c|c|c|c|c|c|c|c|c|c|}
\hline & $\begin{array}{l}R i_{\mathrm{B}}= \\
-2.00\end{array}$ & $\begin{array}{l}R i_{\mathrm{B}}= \\
-1.00\end{array}$ & $\begin{array}{l}R i_{\mathrm{B}}= \\
-0.01\end{array}$ & $\begin{array}{l}R i_{\mathrm{B}}= \\
0.01\end{array}$ & $\begin{array}{l}R i_{\mathrm{B}}= \\
0.07\end{array}$ & $\begin{array}{l}R i_{\mathrm{B}}= \\
0.09\end{array}$ & $\begin{array}{l}R i_{\mathrm{B}}= \\
0.19\end{array}$ & $\begin{array}{l}R i_{\mathrm{B}}= \\
0.21\end{array}$ & $\begin{array}{l}R i_{\mathrm{B}}= \\
1.00\end{array}$ \\
\hline $\begin{array}{l}\text { Launiainen } \\
\text { scheme, } \\
z_{0} / z_{0 h}=0.5\end{array}$ & 5.3 & 3.4 & 0.8 & 0.2 & 16.8 & 5.4 & 8.8 & 10.0 & 36.4 \\
\hline $\begin{array}{c}\text { Present scheme, } \\
z_{0} / z_{0 h}=0.5\end{array}$ & 4.5 & 2.3 & 0.9 & 2.3 & 3.0 & 2.4 & 1.4 & 10.3 & 3.1 \\
\hline $\begin{array}{l}\text { Launiainen } \\
\text { scheme, } \\
z_{0} / z_{0 \mathrm{~h}}=1.0\end{array}$ & 11.2 & 7.3 & 0.8 & 0.1 & 15.7 & 7.0 & 8.4 & 9.3 & 36.6 \\
\hline $\begin{array}{c}\text { Present scheme, } \\
z_{0} / z_{0 \mathrm{~h}}=1.0\end{array}$ & 1.3 & 1.8 & 1.0 & 1.7 & 1.8 & 1.80 & 2.6 & 11.7 & 3.9 \\
\hline $\begin{array}{l}\text { Launiainen } \\
\text { scheme, } \\
z_{0} / z_{0 h}=7.3\end{array}$ & 15.2 & 8.8 & 0.8 & 2.1 & 12.7 & 3.5 & 7.8 & 8.8 & 36.1 \\
\hline $\begin{array}{c}\text { Present scheme, } \\
z_{0} / z_{0 h}=7.3\end{array}$ & 2.0 & 1.7 & 1.4 & 2.0 & 2.3 & 5.0 & 4.8 & 12.4 & 5.9 \\
\hline $\begin{array}{l}\text { Launiainen } \\
\text { scheme, } \\
z_{0} / z_{0 h}=100\end{array}$ & 10.2 & 5.6 & 0.7 & 6.2 & 20.8 & 21.1 & 9.1 & 9.4 & 34.7 \\
\hline $\begin{array}{l}\text { Present scheme, } \\
z_{0} / z_{0 h}=100\end{array}$ & 7.0 & 5.8 & 0.4 & 4.2 & 8.8 & 5.6 & 2.6 & 8.6 & 6.1 \\
\hline
\end{tabular}

Fig. 3). The largest errors in our approach are at the discontinuity where $R i_{\mathrm{B}}=0.2$; for $C_{\mathrm{M}}$ and $C_{\mathrm{H}}$ they are 14 and $11 \%$, respectively. The largest absolute errors of the two schemes for several values of $R i_{\mathrm{B}}$ are also shown in Table $1\left(C_{\mathrm{M}}\right)$ and Table $2\left(C_{\mathrm{H}}\right)$.

\section{Conclusions}

A new non-iterative turbulent-flux parameterization scheme is proposed here that allows a large ratio between the momentum and heat roughness lengths. We use the momentum and heat transfer coefficients obtained by the iterative computations of the Högström (1996) scheme for unstable stratification and of the Beljaars and Holtslag (1991) scheme for stable stratification as references, and improve on Launiainen (1995) approach by using a regression method. This new non-iterative method generates results that agree well with those obtained by iterative computation mentioned above while saving computing time. The advantages of this method are: (i) no iteration, (ii) it allows a large ratio between the momentum and heat roughness lengths, and (iii) high accuracy. Therefore, we recommend its use in weather forecast and climate models.

Acknowledgements This study was supported by the National Program on Key Basic Research Project of China (973) under Grant No. 2010CB428502, by National Natural Science Foundation of China under Grant Nos. 40975009 and 40906023, by China Meteorological Administration under Grant No. GYHY(QX)20076-5 and by the Centurial Program sponsored by the Chinese Academy of Sciences. The National Center for Atmospheric Research is sponsored by the National Science Foundation. We would like to acknowledge J. Launiainen, A. C. M. Beljaars, A. A. M. Holtslag, and U. Högström, whose work made us aware of the confusion surrounding the parameterization of turbulent transfer coefficients in numerical models of the atmosphere. We are very grateful to two anonymous reviewers for their careful reviews and valuable comments, which led to substantial improvements to the manuscript. 


\section{Appendix: The Method for Generating the Equations of the Present Scheme}

With the formulations of Högström (1996) for unstable stratification and Beljaars and Holtslag (1991) for stable stratification, and through iteration, values of $\zeta$ can be generated for various $R i_{\mathrm{B}}$ (in our code, from -2 to 1 with 3000 linear intervals), $z / z_{0}$ (from 100 to $10^{5}$ with $30 \log$-linear intervals) and $z_{0} / z_{0 \mathrm{~h}}$ (from 0.5 to 100 with 20 log-linear intervals). Thus, the values of $\zeta$ form a three-dimensional matrix, one dimension represents the dependence of $\zeta$ on $R i_{\mathrm{B}}$, and two others represent the dependences of $\zeta$ on $\log \left(z_{/} / z_{0}\right)$ and $\log \left(z_{0} / z_{0 \mathrm{~h}}\right)$. Based on the Launiainen (1995) scheme for different stratifications different relationships between $\zeta$ and $R i_{\mathrm{B}}$ are assumed:

$$
\zeta=A R i_{\mathrm{B}}+B
$$

for $R i_{\mathrm{B}}>0.2$

$$
\zeta=A R i_{\mathrm{B}}^{2}+B R i_{\mathrm{B}}
$$

for $R i_{\mathrm{B}}<0$ or $0<R i_{\mathrm{B}} \leq 0.2$.

With these relationships, and through regression analysis, for each stratification we can downsize the three-dimensional matrix of $\zeta$ into two two-dimensional matrices, one matrix contains the values of $A$ and the other contains the values of $B$. We assume that $A$ and $B$ can be expressed as a Taylor series expansion in $\log \left(z / z_{0}\right)$ :

$$
\begin{aligned}
& A=c_{\mathrm{m}} \log ^{m-1}\left(z / z_{0}\right)+\cdots+c_{k} \log ^{k-1}\left(z / z_{0}\right)+\cdots c_{1}, \\
& B=d_{\mathrm{n}} \log ^{n-1}\left(z / z_{0}\right)+\cdots+d_{k} \log ^{k-1}\left(z / z_{0}\right)+\cdots d_{1} .
\end{aligned}
$$

With the two equations, we can downsize the two-dimensional matrices of $A$ and $B$ into $(\mathrm{m}+\mathrm{n})$ one-dimensional matrices, each matrix contains the values of $c_{k}(k=1,2, \ldots, m)$ and $d_{k}(k=1,2, \ldots, n)$. We assume $c_{k}$ and $d_{k}$ can be expressed as a Taylor series expansion in $\log \left(z_{0} / z_{0 h}\right)$,

$$
\left\{\begin{array}{l}
c_{k}=a_{p_{k}} \log ^{p_{k}-1}\left(z_{0} / z_{0 \mathrm{~h}}\right)+\cdots+a_{i_{k}} \log ^{i_{k}-1}\left(z_{0} / z_{0 \mathrm{~h}}\right)+\cdots a_{1_{k}}, \quad k=1,2, \ldots, m, \\
d_{k}=b_{q_{k}} \log ^{q_{k}-1}\left(z_{0} / z_{0 \mathrm{~h}}\right)+\cdots+b_{i_{k}} \log ^{j_{k}-1}\left(z_{0} / z_{0 \mathrm{~h}}\right)+\cdots b_{1_{k}}, \quad k=1,2, \ldots, n .
\end{array}\right.
$$

The $(\mathrm{m}+\mathrm{n})$ one-dimensional matrices can be downsized to $(m \times p+n \times q)$, which are the values of $a_{i_{k}}(i=1,2, \ldots, p, k=1,2, \ldots, m)$ or $b_{j_{k}}(j=1,2, \ldots, q, k=1,2, \ldots, n)$. Thus, we have all the coefficients of the equations $\zeta=f\left(R i_{\mathrm{B}}, \log \left(z_{2} / z_{0}\right), \log \left(z_{0} / z_{0 \mathrm{~h}}\right)\right)$ for different stratifications. However, these equations are too complex, and many terms are unimportant. To check the significance of each term, the equations with and without each specific term are tested: if without this specific term, the new equation's mean deviation from the iteration result still stays within a small range (to attain the most accurate regression results and also the simplest equations, $5 \%$ is chosen for the unstable and weakly stable conditions, $2 \%$ is chosen for the strongly stable condition), then this specific term is considered unimportant and can be deleted. Finally, several terms remain and the final forms of the three equations are as Eqs. 12, 14 and 16, and the mean deviations from the iteration results are 4.0, 4.1 and $1.4 \%$, respectively. 


\section{References}

Beljaars ACM, Holtslag AAM (1991) Flux parameterization over land surfaces for atmospheric models. J Appl Meteorol 30:327-341

Businger JA, Wyngaard JC, Izumi Y, Bardley EF (1971) Flux-profile relationships in the atmospheric surface layer. J Atmos Sci 28:181-189

Delage Y (1997) Parameterising sub-grid scale vertical transport in atmospheric models under statically stable conditions. Boundary-Layer Meteorol 82:23-48

Dyer AJ (1974) A review of flux-profile relationships. Boundary-Layer Meteorol 7:363-372

European Centre for Medium-Range Weather Forecasts (1988) Proceedings of ECMWF workshop on parameterization of fluxes over land surfaces. Eur Cent for Medium-Range Weather Forecasts, Reading, England, $392 \mathrm{pp}$

Fairall CW, Bradley EF, Rogers DP, Edson JB, Young GS (1996) Bulk parameterization of air-sea fluxes for TOGA COARE. J Geophys Res 101:3747-3764

Garratt JR (1992) The atmospheric boundary layer. Cambridge University Press, UK, $316 \mathrm{pp}$

Garratt JR, Pielke RA (1989) On the sensitivity of mesoscale models to surface-layer parameterization constants. Boundary-Layer Meteorol 48:377-387

Guilloteau E (1998) Optimized computation of transfer coefficients in surface layer with different momentum and heat roughness lengths. Boundary-Layer Meteorol 87:147-160

Högström U (1996) Review of some basic characteristics of the atmospheric surface layer. Boundary-Layer Meteorol 78:215-246

Holtslag AAM, de Bruin HAR (1988) Applied modelling of the nighttime surface energy balance over land. J Appl Meteorol 22:689-704

Kot SC, Song Y (1998) An improvement to the Louis scheme for the surface layer in an atmospheric modeling system. Boundary-Layer Meteorol 88:239-254

Launiainen J (1995) Derivation of the relationship between the Obukhov stability parameter and the bulk Richardson number for flux-profile studies. Boundary-Layer Meteorol 76:165-179

Louis JF (1979) A parametric model of vertical eddy fluxes in the atmosphere. Boundary-Layer Meteorol 17:187-202

Louis JF, Tiedtke M, Geleyn JF (1982) A short history of the operational PBL-parameterization at ECMWF. In: Workshop on planetary boundary layer parameterization, Shinfield Park, Reading, UK, European Centre for Medium Range Weather Forecasts, pp 59-79

Mascart P, Noilhan J, Giordani H (1995) A modified parameterization of flux-profile relationship in the surface layer using different roughness length values for heat and momentum. Boundary-Layer Meteorol 72:331-344

Monin AS, Obukhov AM (1954) Basic regularity in turbulent mixing in surface layer of the atmosphere. Akad Nauk SSSR Geofiz Inst 24:163-187

Uno I, Cai XM, Steyn DG, Emori S (1995) A simple extension of the Louis method for rough surface layer modelling. Boundary-Layer Meteorol 76:395-409

Vanden Hurk BJJM, Holtslag AAM (1997) On the bulk parameterization of surface layer fluxes for various conditions and parameter ranges. Boundary-Layer Meteorol 82:119-134

Wang SP, Wang Q, Doyle J (2002) Some improvements to Louis surface parameterization. Paper presented at 15th symposium on boundary layers and turbulence, American Meteorological Society, 15-19 July 2002, Wageningen, Netherlands 